OPEN ACCESS

Edited by:

Marina Pajic,

Garvan Institute of Medical Research,

Australia

Reviewed by:

Imayavaramban Lakshmanan, University of Nebraska Medical Center,

United States

Jaques Waisberg,

Faculdade de Medicina do ABC, Brazil

${ }^{*}$ Correspondence:

Peilin Cui

cuip/@aliyun.com

${ }^{\dagger}$ These authors have contributed equally to this work

Specialty section:

This article was submitted to Gastrointestinal Cancers,

a section of the journal

Frontiers in Oncology

Received: 25 December 2019

Accepted: 21 January 2021

Published: 09 March 2021

Citation:

Li C, Dou X, Sun J, Xie M, Li H and Cui $P$ (2021) Wnt7a Promotes the

Occurrence and Development of Colorectal Adenocarcinoma.

Front. Oncol. 11:522899. doi: 10.3389/fonc.2021.522899

\section{Wnt7a Promotes the Occurrence and Development of Colorectal Adenocarcinoma}

\author{
Congcong $\mathrm{Li}^{1,2+}$, Xiaowei $\mathrm{Dou}^{3+}$, Jiahuan Sun ${ }^{4}, \mathrm{Min} \mathrm{Xie}^{4}$, Hongli $\mathrm{Li}^{4}$ and Peilin Cui ${ }^{1 *}$ \\ 1 Department of Gastroenterology, Beijing Tiantan Hospital, Capital Medical University, Beijing, China, ${ }^{2}$ Department of \\ Oncology, Pudong Hospital Affiliated to Fudan University, Shanghai, China, ${ }^{3}$ Clinical Medical Research Center, Guizhou \\ Medical University, Guiyang, China, ${ }^{4}$ Gastrology Department, Beijing Tiantan Hospital, Capital Medical University, Beijing, \\ China
}

Objective: The expression of Wnt7a in colorectal cancer tissues and cell lines was analyzed, and the effect of Wnt7a on the proliferation of colorectal cancer cells was studied, so as to confirm the relationship between Wnt7a and the occurrence and development of colorectal cancer.

Methods: (1) Immunohistochemical method was used to compare the expression of Wnt7a in different tissues and its relationship with the clinicopathology of colorectal adenocarcinoma. (2) The expression levels of Wnt7a in colorectal cancer cell lines HT-29 and HCT 116 were detected by GRT-PCR. (3) The down-regulated Wnt7A expression vector was constructed, and the down-regulated Wnt7A expression cell line was established. The regeneration ability of cancer cells was detected by stem cell ball formation assay, and the influence of plate cloning assay on the proliferation ability of colorectal cancer cells was detected.

Results: (1) The positive rates of Wnt7a in normal colorectal mucosa, colorectal adenoma and colorectal adenocarcinoma tissues gradually increased,Wnt7a are closely related to the degree of colorectal adenocarcinoma differentiation, lymph node metastasis and Duke stage. (2) The expression level of Wnt7a in colorectal cancer cells was higher than that in normal colorectal epithelial cells. (3) The down-regulation of Wnt7A reduced the proliferation ability of colorectal cancer cells.

Conclusions: Wnt7a promotes the occurrence and development of colorectal adenocarcinoma.

Keywords: colorectal cancer, Wnt7a, occurrence, development, proliferation

\section{INTRODUCTION}

Colorectal cancer is one of the most common malignant tumors in the world. Its global comprehensive incidence rate ranks third among men in malignant tumors and second among women (1). Colorectal cancer is the second leading cause of cancer death in the word $(2,3)$. In China, the number of new cases of colorectal cancer and the number of cases of death has also increased year by year. From 2008 to 2013, the incidence of colorectal cancer in China has risen 
from $14.6 / 100,000$ to $17.2 / 100,000$. The mortality rate has risen from $6.18 / 100,000$ to $7.76 / 100,000$ (4). In China, more than $50 \%$ of patients with colorectal cancer miss the ideal time for treatment, and the 5-year survival rate is less than $40 \%$ (5). Therefore, early identification and diagnosis of colorectal cancer as well as early intervention can improve the survival rate of colorectal cancer. Several new markers have been identified as either positive or negative indicators of the disease, which indicates that complementary biomarkers may contribute to risk assessment and aid in the personalized treatment of CRC patients (6-8). Histological and serological samples are also easily collected from patients. Thus, the discovery of more prognostic biomarkers for CRC can help predict patient outcomes and provide a novel therapeutic target.

Wnt7a is closely related to a variety of tumors. (1) Wnt7a exerts a tumor suppressor effect in various cancers. OchoaHernandez AB (9) demonstrated its role in leukemia, showing through the construction of overexpressing virus that Wnt7a is expressed in leukemia cell lines and Wnt7a expression in normal peripheral blood $\mathrm{T}$ lymphocytes is significantly higher than in leukemia cells. Calvo R (10) and Ohira T et al. (11) found that Wnt7a may play a tumor suppressor role in lung cancer (especially non-small cell lung cancer), finding that Wnt7a is down-regulated in non-small cell lung cancer. Ohira T et al. also found that Wnt7a plays an important tumor suppression role in lung cancer, which may be related to the absence of E-cadherin. (2) Wnt7a also plays a carcinogenic role. Yoshioka S et al. (12) injected Wnt7a ovarian cancer cells and Wnt7a-expressing ovarian cancer cells into nude mice, and then found that Wnt7a ovarian cancer SKOV3ip1 was knocked out. Tumor lesions and cell invasion in the cell group were relatively small. Carmon KS et al. (13) found in endometrial cancer cells by coimmunoprecipitation that Wnt7a activates the canonical Wnt/ $\beta$ catenin signaling pathway by binding to Fzd5, which ultimately leads to cell proliferation. However, current studies on Wnt7a and colorectal cancer are few and preliminary.

In the present work, we analyzed the expression of Wnt7a in colorectal cancer tissues and cell lines, and studied the effect of Wnt7a on the proliferation of colorectal cancer cells, so as to confirm the relationship between Wnt7a and the occurrence and development of colorectal cancer.

\section{METHODS}

Immunohistochemical method was used to compare the expression of Wnt7a in different tissues and its relationship with the clinicopathology of colorectal adenocarcinoma.

\section{Patients and Tumor Specimens}

Eighty specimens from the Department of Gastroenterology and General Surgery of Beijing Tiantan Hospital affiliated with Capital Medical University from June 2013 to March 2017 were collected and confirmed by pathology as colorectal adenocarcinoma. There were 49 males and 31 females; aged $24-73$ years, mean age $(54.88 \pm 10.32)$ years old, 45 cases less than 65 years old, 35cases older than 65 years; 26 cases of rectal adenocarcinoma, 54 cases of colon adenocarcinoma; 51 cases with diameter $\leq 5 \mathrm{~cm}, 29$ cases with diameter $>5 \mathrm{~cm}$; 55 cases with infiltration into serosal layer, 25 cases without infiltration into the serosal layer; 25 cases with highly differentiated adenocarcinoma, 22 cases with moderately differentiated adenocarcinoma, 33 cases with low differentiated adenocarcinoma; 28 cases without lymph node metastasis, 52 cases with lymph node metastasis; 9 cases with distant metastasis, 71 cases with no distant metastasis; There were 32 cases with TNM stage I+II and 48 cases with TNM stage III+IV. All cases occurred with no other tumors, no tumor bleeding, intestinal perforation, intestinal obstruction, acute or chronic infection. In the control group, 20 normal tissues and 40 benign colon adenomas were selected. The appropriate paraffin tissue specimens were selected and serially sectioned $4 \mu \mathrm{m}$ thick for immunohistochemical staining, screened by two pathologists, and the final results were confirmed.

\section{Immunohistochemistry Staining}

Immunohistochemical analysis for Wnt7a was performed on 80 CRC specimens. The paraffin-embedded, formalin-fixed tissues were cut into $4-\mathrm{mm}$ sections and dried at $70^{\circ} \mathrm{C}$ for $2 \mathrm{~h}$. After deparaffinization and hydration, sections were rinsed in phosphate buffered saline (PBS) and then immersed in 3\% hydrogen peroxide for $10 \mathrm{~min}$ to block endogenous peroxidase activity. Antigen retrieval was performed in boiled citrate buffer ( $\mathrm{pH}$ 6.0) for $10 \mathrm{~min}$. The slides were incubated with Wnt7a primary antibody (goat polyclonal 1:50, AF3008; R\&D, Minneapolis, MN, USA) at $4^{\circ} \mathrm{C}$ overnight. After incubation with the secondary antibody for $30 \mathrm{~min}$, sections were stained with 3,3'-diaminobenzidine (DAB) for $10 \mathrm{~min}$, lightly counterstained with 10\% Mayer's hematoxylin, dehydrated, and mounted.

\section{Immunohistochemical Evaluation}

The staining was assessed by a semi-quantitative analysis and a protein level score which is equal to the positive cell proportion score added to the cell staining score. A well-stained area was selected and observed in 10 high-power fields continuously, and more than 50 cells per field were observed. The procedure outlined in Wang Aimin, et al. (14) was then followed to calculate the proportion of stained cells. If the proportion of positive cells < $10 \%$, the score is 0 ; if the proportion of positive cells is between $10 \%$ and $40 \%$ the score is 1 ; if the proportion of positive cells is between $40 \%$ and $70 \%$ the score is 2 ; if the proportion of positive cells is $\geq 70 \%$ the score is 3 . The scores designate: no coloration ( 0 points); yellow staining (1 point); brownish yellow staining (2 points); yellowish brown staining (3 points). Final protein level scores are as follows: 0 is negative, $1-3$ is + , and $4-6$ is ++ . Two pathologists analyzed the stained tissue sections and they were blinded to the patient's clinical parameters.

\section{Western Blot}

Total protein was extracted and lysed with RIPA buffer containing protease inhibitor cocktail (Roche). The proteins were separated by SDS-PAGE electrophoresis and transferred to membrane. Membranes were probed with specific primary antibodies against 
$\beta$-actin (Santa Cruz), Wnt7a (abcam), and detected by horseradish peroxidase-conjugated secondary antibodies.

The expression levels of Wnt7a in colorectal cancer cell lines HT-29 and HCT 116 were detected by qRT-PCR.3. The downregulated Wnt7A expression vector was constructed, and the down-regulated Wnt7A expression cell line was established. The regeneration ability of cancer cells was detected by stem cell ball formation assay, and the influence of plate cloning assay on the proliferation ability of colorectal cancer cells was detected.

\section{Cell Lines}

Two human colorectal cancer cell lines HT-29, HCT 116 cells were purchased from the Chinese Academy of Sciences Cell Bank (Shanghai, China). A normal colorectal epithelial cell line, HCOEPIC, was purchased from a laboratory in Carlsbad, California, USA.

\section{Cell Culture}

Colorectal cancer cell lines HT-29 and HCT 116 were cultured in a constant temperature and humidity incubator containing 5\% $\mathrm{CO}_{2}$ at $37^{\circ} \mathrm{C}$ using complete medium (containing McCoys5 $\mathrm{A}$ medium, $10 \%$ fetal bovine serum, $100 \mathrm{U} / \mathrm{ml}$ penicillin and 100 $\mathrm{ug} / \mathrm{ml}$ streptomycin). in. According to the cell growth condition, the medium was cultured once every $2-3$ days, and when the cells covered most of the surface of the bottom wall of the bottle, the cells were passaged or collected.

\section{Vector Construction and Lentivirus Synthesis}

Expression of Wnt7a was inhibited by small hairpin RNA (shRNA) technology constructing a lentiviral vector. The lentivirus vector for silencing Wnt7A were ordered from sigma. The target sequence for shRNA were: shWnt7A-b: GCGTTCACCTACGCCATCATT; shWnt7A-c: CATAGGAGAAGGCTCACAAAT. The sequence coding human Wnt7A was amplified by reverse transcriptase polymerase chain reaction (RT-PCR): (forward primer: 5'TTGGCGCGCCGCCACCATGAACCGGAAAGCGCGGCG-3' and reverse primer: primers: 5'-CCTTAATTAATCACTTGC ACGTGTACATCT-3') and inserted into the AscI/PacI sites of $\mathrm{pCDH}$. The shRNA or $\mathrm{pCDH}$ were cotransfected with packaging vector psPAX2 and MD2G overnight and changed medium. 48 and $72 \mathrm{~h}$ after transfection, the viral was collected and infected HT29 or HCT116 cells in the presence of $8 \mathrm{ug} / \mathrm{ul}$ polybrene overnight. The cells for silencing Wnt7a were selected by puromycin.

\section{qRT-PCR}

Total RNA was isolated using Trizol reagent (Invitrogen), and reverse-transcription wre performed using PrimeScript ${ }^{\mathrm{TM}}$ RT reagent Kit (Takara) according to manufacturer's instructions. Real-time PCR were performed using SYBR Premix Ex Taq II (Takara). The following primers were used: Wnt7A (5'CTGTGGCTGCGACAAAGAGAA-3' and 5'-GCCGTGGCA CTTACATTCC-3'), CyclinD1 (5'-GCTGCGAAGTGGAA ACCATC-3' and 5'-CCTCCTTCTGCACACATTTGAA-3') and Cyclin E1 (5'- AAGGAGCGGGACACCATGA-3' and 5'ACGGTCACGTTTGCCTTCC-3'). The primer for internal control $\beta$-actin (5'-GAGACCTTCAACACCCCAGCC-3' and
5'- AATGTCACGCACGATTTCCC-3'). The Real-time PCR were carried out by the CFX96 Real-time PCR Detection System (BIO-RAD). Each sample was done in triplicate and $\beta$-actin was used as a reference for normalization. The relative expression level was evaluated through Normalized Gene Expression (ddCT) by the CFX96 data analysis software.

\section{Sphere Formation Assay}

The colorectal cancer cells (HT-29 HCT 116) were digested with typsine and filtered with a 40-um strainer. The cells were grown in serum-free DMEM/F-12 (Gibco) supplemented with $10 \mathrm{ng} / \mathrm{ml}$ human recombinant bFGF (basic fibroblast growth factor; R\&D), $10 \mathrm{ng} / \mathrm{ml}$ EGF (epidermal growth factor; Gibco) and B27 (Gibco). The cells were cultured in $2 \mathrm{ml}$ medium in each well of a 6-well ultralow attachment plate and medium was added every 3 days. The size of tumorsphere were evaluated after 7 days of culture. Each experiment was performed in triplicate and measured by two investigators.

\section{Plate Clone Formation Assay}

The cells in the logarithmic growth phase were digested with $0.25 \%$ trypsin and blown into individual cells, and the cells were suspended in DMEM medium containing 10\% fetal bovine serum for use. 2 . The cell suspension was diluted as a gradient. Each group of cells was inoculated with $10 \mathrm{~mL}$ of $37^{\circ} \mathrm{C}$ pre-warmed culture medium at a gradient density of 50,100, and 200 cells per dish, and gently rotated to disperse the cells evenly. It was then incubated in a cell culture incubator at $37^{\circ} \mathrm{C} 5 \% \mathrm{CO}_{2}$ and saturated humidity for 2 to 3 weeks. 3. It is often observed that when macroscopic clones appear in the culture dish, the culture is terminated. The supernatant was discarded and carefully immersed twice in PBS. Add 4\% paraformaldehyde fixed cells to $5 \mathrm{~mL}$ for $15 \mathrm{~min}$. Then, the appropriate amount of GIMSA application staining solution was for 10 to $30 \mathrm{~min}$, and slowly washed away with running water and air dried. 4. The plate was inverted and a grid of transparencies was overlaid. The clones were counted directly. Finally, the clone formation rate was calculated. Clonal formation rate $=$ (number of clones/number of cells inoculated) $\times 100 \%$.

\section{Statistical Analysis}

SPSS 19.0 was used for statistical analysis. Measurement data that conform to the normal distribution are expressed as mean \pm standard deviation $(\mathrm{x} \pm \mathrm{s})$, independent sample t-test or one-way ANOVA were used for comparison between groups, and nonnormal distribution is expressed by median and interquartile range; In terms of percentage, the comparison between the positive rates was performed by $\chi 2$ test; the correlation analysis of the two variables was performed by $\chi 2$ test or Spearman correlation analysis, the test level was 0.05 , and the two-sided test was used. $\mathrm{P}<0.05$ was statistically significant.

\section{RESULTS}

(1) The expression of Wnt7a was assessed in normal colonic mucosa, colorectal adenoma and colorectal cancer tissues. 
The positive expression rate of $\mathrm{Wnt7}$ a in colorectal adenocarcinoma was significantly higher than that in colorectal adenoma and normal colorectal mucosa $(\mathrm{P}<0.01)$ (Table 1) (Figure 1).

(2) Correlation between immunohistochemical wnt7a expression and clinicopathological.

The positive expression of $\mathrm{Wnt7}$ a protein was not related to the gender, age, lesion location, path length, depth of invasion, and distant metastasis $(\mathrm{P}>0.05)$, but was related to the TNM stage, cell differentiation, and lymph node metastasis. Clinical pathological parameters were associated $(\mathrm{P}<0.01)$. The lower the degree of differentiation, the higher the stage and the colorectal cancer with lymph node metastasis, the higher the positive rate of Wnt7a (Table 2).

(3) The expression level of Wnt7a in colorectal cancer cell lines HT-29 and HCT 116 was higher than that in normal colon epithelial cell lines HCoEpic (Figure 2).

(4) The knockout of Wnt7A gene inhibited the proliferation of colon cancer cells.

To investigate the effect of Wnt7a on the proliferation of colorectal cancer cells, we first silenced Wnt7a in colon cancer cell lines HT29 and HT116. Real-time PCR confirmed that SHWNT7B and SHWNT7C effectively silenced WNT7A expression at the protein and mRNA levels (Figure 3).After culture with pellet forming medium, Wnt7A knockout reduced the number of tumor globules in HT29 and HT116 cells. Clonal

TABLE 1 | Expression of Wnt7a in three different colon tissues.

\begin{tabular}{|c|c|c|c|c|c|}
\hline \multirow[t]{2}{*}{ Tissue type } & \multirow[t]{2}{*}{$\mathbf{N}$} & \multicolumn{2}{|c|}{$\begin{array}{c}\text { Wnt7a protein } \\
\text { positive } \\
\text { expression rate }\end{array}$} & \multirow[t]{2}{*}{ Positive rate (\%) } & \multirow[t]{2}{*}{$\mathbf{P}$} \\
\hline & & Positive & Negative & & \\
\hline Normal mucosal tissue & 20 & 4 & 16 & 20 & \\
\hline Colorectal adenoma & 40 & 13 & 27 & 32.5 & 0.31 \\
\hline $\begin{array}{l}\text { Colorectal } \\
\text { adenocarcinoma }\end{array}$ & 80 & 54 & 26 & 67.5 & 0.00 \\
\hline $\begin{array}{l}\chi^{2} \\
P\end{array}$ & \multicolumn{5}{|c|}{21.876} \\
\hline
\end{tabular}

*indicates a $P$ value less than 0.05 . formation assay was used to detect the effect of knockdown Wnt7a on colonization ability of colon cancer cells. After knockdown of Wnt7A, the number of clone formation of HT29 and HCT 116 of colon cancer cells was significantly reduced compared with the control group. These results suggest that silencing Wnt7a inhibits colon cancer proliferation (Figures 4 and 5).

\section{DISCUSSION}

In recent years, with the change of people's lifestyle, the strengthening of awareness of early diagnosis and early treatment, as well as the gradual progress of colorectal cancer surgery, radiotherapy and chemotherapy technology, the 5-year survival rate of colorectal cancer is still only $66.1 \%$, and if distant metastasis occurs, the 5-year survival rate of patients is as low as $12.5 \%$ (15). The high morbidity and mortality of colorectal cancer have a great impact on the social and family life of patients and their families. How to find the biomarkers that can diagnose colorectal cancer early and predict the prognosis of colorectal cancer has become a research hotspot around the world.

Wnt7a is an important protein in the Wnt signaling pathway. A number of studies have shown that Wnt7a plays an oncogenic or anticancer role in a variety of tumors. Currently, the studies on Wnt7 a and colorectal cancer are still in the preliminary stage, so the study on its influence on the occurrence and development of colorectal cancer may provide a new idea for the diagnostic treatment of colorectal cancer.

The conclusion of this study suggests that the positive expression of Wnt7a in colon adenocarcinoma is significantly higher than that in colorectal adenoma and normal colorectal mucosa. In addition, by studying the relationship between Wnt7a and clinical pathological parameters of colorectal cancer, it suggests that Wnt7a can be used as a reference index to evaluate the malignant degree and metastasis of colorectal cancer, and provide a reference for the prognosis of colorectal cancer. However, the number of experimental studies is small, the results of research may have some deviation, and follow up studies have not been done. Therefore, the prognosis cannot be

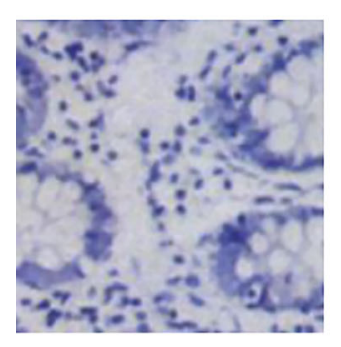

Negative expression in normal tissues (X200)

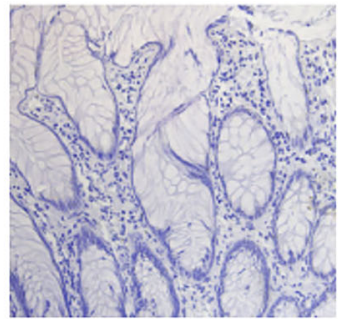

Expression in colonic

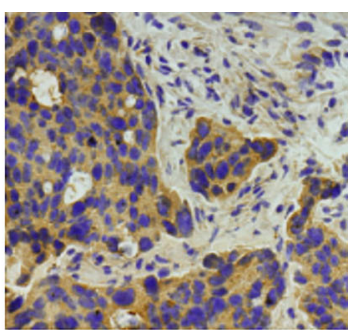

Positive expression in colon cancer tissue (X200)

FIGURE 1 | Immunohistochemical results of Wnt7a in normal tissues, colonic adenoma tissues and colonic adenocarcinoma tissues. 
TABLE 2 | Correlation between Wnt7 $\alpha$ expression and clinicopathological information in primary CRC.

\begin{tabular}{|c|c|c|c|c|c|c|c|}
\hline \multirow[t]{2}{*}{ Characteristic } & \multirow[t]{2}{*}{ No. of cases } & \multicolumn{6}{|c|}{ Wnt7a } \\
\hline & & - & + &,+++++ & Positive rate & $\chi^{2}$ & $\mathbf{P}$ \\
\hline \multicolumn{8}{|l|}{ Gender } \\
\hline Male & 49 & 14 & 8 & 27 & $71.4 \%$ & 0.890 & 0.346 \\
\hline Female & 31 & 12 & 6 & 13 & $61.3 \%$ & & \\
\hline \multicolumn{8}{|l|}{ Age (years) } \\
\hline$<65$ & 45 & 15 & 10 & 20 & $66.7 \%$ & 0.033 & 0.857 \\
\hline$\geq 65$ & 35 & 11 & 9 & 15 & $68.6 \%$ & & \\
\hline \multicolumn{8}{|l|}{ location } \\
\hline Colon & 26 & 10 & 5 & 11 & $61.5 \%$ & 0.624 & 0.430 \\
\hline Rectu & 54 & 16 & 9 & 29 & $70.4 \%$ & & \\
\hline \multicolumn{8}{|l|}{ Tumor size } \\
\hline$\leq 5 \mathrm{~cm}$ & 51 & 18 & 9 & 24 & $64.7 \%$ & 0.501 & 0.479 \\
\hline$>5 \mathrm{~cm}$ & 29 & 8 & 6 & 15 & $72.4 \%$ & & \\
\hline \multicolumn{8}{|l|}{ Depth } \\
\hline Undiluted serosa & 25 & 10 & 6 & 930 & $60 \%$ & 0.932 & 0.334 \\
\hline Infiltrated serosa & 55 & 16 & 9 & 30 & $70.9 \%$ & & \\
\hline \multicolumn{8}{|l|}{ Histological grade } \\
\hline Well/moderate & 47 & 21 & 20 & 6 & $55.3 \%$ & 7.706 & $0.005^{\star}$ \\
\hline Poor & 33 & 5 & 7 & 21 & $84.8 \%$ & & \\
\hline \multicolumn{8}{|c|}{ Lymph node metastasis } \\
\hline Present & 52 & 9 & 7 & 36 & $82.7 \%$ & 15.631 & $0.00^{\star}$ \\
\hline Absent & 28 & 17 & 2 & 9 & $39.3 \%$ & & \\
\hline \multicolumn{8}{|l|}{ Vascular invasion } \\
\hline Present & 9 & 3 & 1 & 5 & $66.7 \%$ & 0.003 & 0.955 \\
\hline Absent & 71 & 23 & 10 & 38 & $67.6 \%$ & & \\
\hline \multicolumn{8}{|l|}{ TNM staging } \\
\hline $1+\|$ & 32 & 15 & 4 & 13 & $53.1 \%$ & 5.024 & $0.025^{\star}$ \\
\hline III+IV & 48 & 11 & 8 & 29 & $77.1 \%$ & & \\
\hline
\end{tabular}

*indicates a $P$ value less than 0.05 .

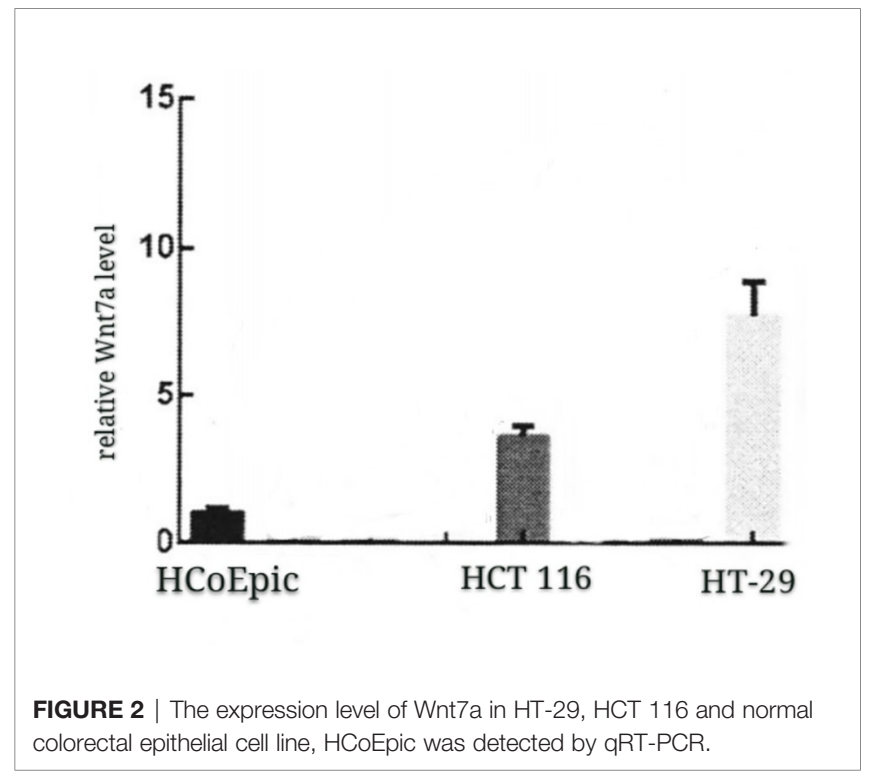

accurately evaluated and further optimization is needed. In addition, to investigate the potential role of $\mathrm{Wnt7a}$ in colon cancer tumorigenesis, Wnt7a was silenced in the colon cancer cell lines HT29 and HT116. Real-time PCR confirmed that shWnt7b and shWnt7c effectively silenced Wnt7a expression at mRNA levels. Thus, we surmise that Wnt7 $\alpha$ plays a key role in the transformation process from adenoma to carcinoma by

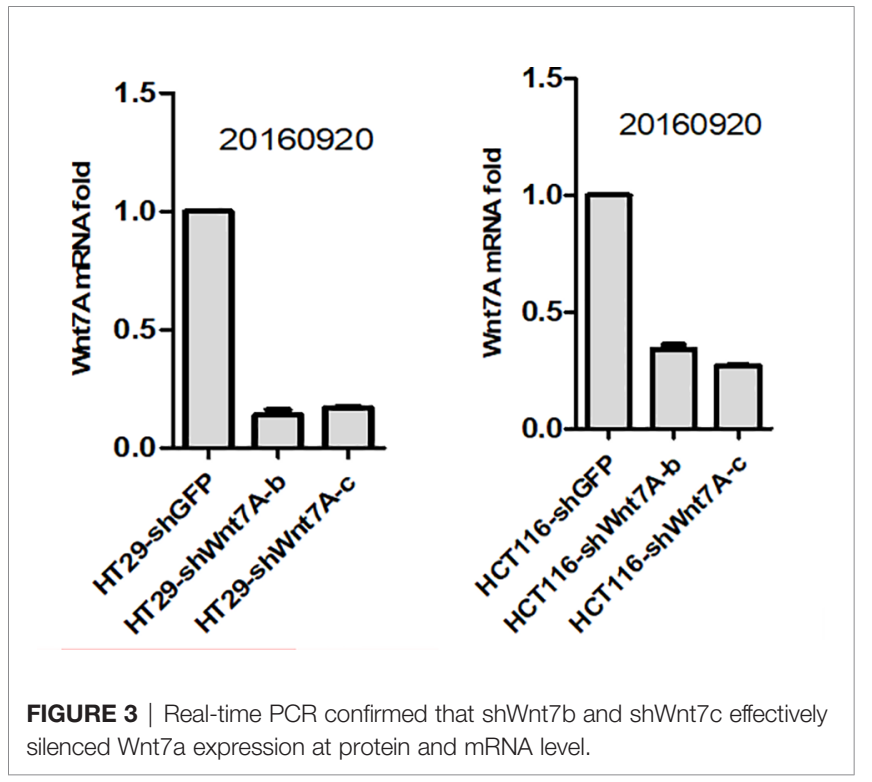

promoting cancer cell growth and metastasis. In this study, siRNAs specific to Wnt7A were transfected into 2 colon cancer cell lines. Real-time PCR was used to verify the knockdown efficiency. Then, sphere formation experiment and plate clone formation experiment were carried out in vitro to verify the effect of Wnt7a on the growth of colon cancer cells. After knockdown of Wnt7A, the proliferation rate of colorectal cancer cells was slowed 


\section{HT29}

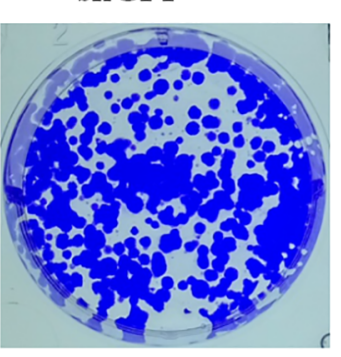

shWnt7A-b

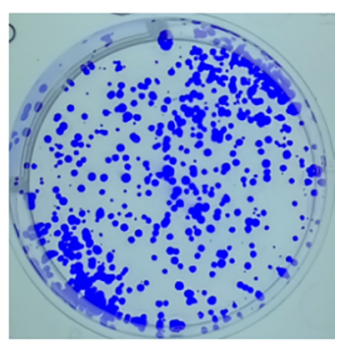

HCT 116
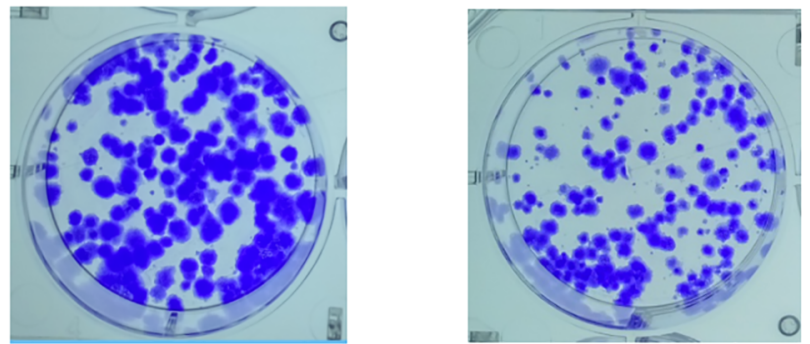

FIGURE 4 | Colony formation assay.

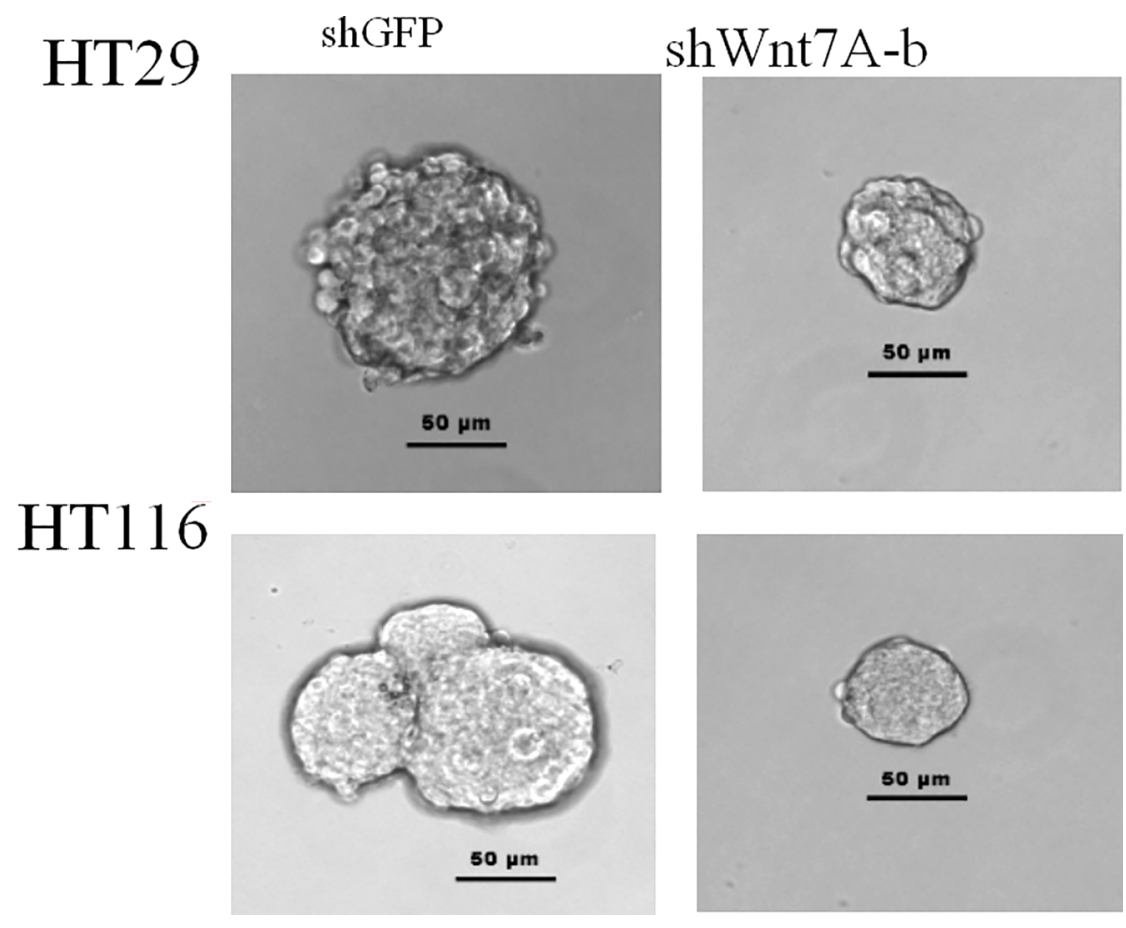

FIGURE 5 | Sphere formation assay. 
down and the ability of clone formation was reduced, which proved that Wnt7A could promote the growth of colorectal cancer cells.

The results of this study only reveal associations, and further study is necessary to investigate the potential mechanism of Wnt7a in CRC development.

\section{DATA AVAILABILITY STATEMENT}

The data used during the current study are available from the corresponding author on reasonable request.

\section{ETHICS STATEMENT}

This study was approved by the Medical Ethics Committee of Beijing Tiantan Hospital, Capital Medical University, Beijing,

\section{REFERENCES}

1. Nusse R, Brown A, Papkoff J, Scambler P, Shackleford G, McMahon A, et al. A new nomenclature for int-land related genes, the wnt gene family. Cell (1991) 64:231-2. doi: 10.1016/0092-8674(91)90633-A

2. Hsieh JC, Kodjabachian L, Rebbert ML, Rattner A, Smallwood PM, Samos $\mathrm{CH}$, et al. A new secreted protein that binds to Wnt proteins and inhibits their activities. Nature (1999) 398(6726):431-6. doi: 10.1038/18899

3. Dann CE, Hsieh JC, Ratmer A, Sharma D, Nathans J, Leahy DJ, et al. Insights into Wnt binding and signalling from the structures of two Frizzled cysteine-rich domains. Nature (2001) 412(6842):86-90. doi: 10.1038/ 35083601

4. Willert K, Brown JD, Danenberg E, Duncan AW, Weissman IL, Reya T, et al. Wnt proteins are lipid-modified and Can act aS stem cell growth factors. Nature (2003) 423(6938):448-52. doi: 10.1038/nature01611

5. RAO TP, KUHL M. An updated overview on Wnt signaling pathways: a prelude for more. Circ Res (2010) 106(12):1798-806. doi: 10.1161/ CIRCRESAHA.110.219840

6. Xu J, Wan XB, Huang XF, Chan KC, Hong MH, Wang LH, et al. Serologic antienzyme rate of Epstein-Barr virus DNase-specific Neutralizing antibody segregates TNM classification in nasopharyngeal carcinoma. J Clin Oncol (2010) 28:5202-9. doi: 10.1200/JCO.2009.25.6552

7. Fan XJ, Wan XB, Fu XH, Wu PH, Chen DK, Wang PN, et al. Phosphorylated p38, a negative prognostic biomarker, complements TNM staging prognostication in colorectal cancer. Tumour Biol (2014) 35:10487-95. doi: 10.1007/s13277-014-2320-3

8. Fang Y, Jiang Y, Wang X, Yang X, Gao Y, Wang J. Somatic mutations of the HER2 in metastatic breast cancer. Tumour Biol (2014) 35:11851-4. doi: 10.1007/s13277-014-2414-y

9. Ochoa-Hernandez AB, Ramos-Solano M, Meza-Canales ID, Garcia-Castro B, Rosales-Reynoso MA, Rosales-Avina JA, et al. Peripheral T-lymphocytes express
China. Written informed consent to participate in this study was obtained from all patients at the time of admission.

\section{AUTHOR CONTRIBUTIONS}

$\mathrm{CL}$ and XD contributed equally to this work. All authors contributed to the article and approved the submitted version.

\section{ACKNOWLEDGMENTS}

We acknowledge the generous support of the Clinical Research Center, the Affiliated Hospital of Guizhou Medical University, Department of Gastroenterology Beijing Tiantan Hospital, Capital Medical University.

WNT7A and its restoration in leukemia-derived lymphoblasts inhibits cell proliferation. BMC Cancer (2012) 12:60. doi: 10.1186/1471-2407-12-60

10. Calvo R, West J, Franklin W, Erickson P, Bemis L, Li E, et al. Altered HOX and WNT7A expression in human lung cancer. Proc Natl Acad Sci USA (2000) 97 (23):12776-81. doi: 10.1073/pnas.97.23.12776

11. Ohira T, Gemmill RM, Ferguson K, Kusy S, Roche J, Brambilla E, et al. WNT7a induces E-cadherin in lung cancer cells. Proc Natl Acad Sci USA (2003) 100(18):10429-34. doi: 10.1073/pnas.1734137100

12. Yoshioka S, King ML, Ran S, Okuda H, MacLean J, McAsey M, et al. WNT7A Regulates Tumor Growth and Progression in Ovarian Cancer through the WNT/ $\beta$-Catenin Pathway. Mol Cancer Res (2012) 10(3):469-82. doi: 10.1158/ 1541-7786.MCR-11-0177

13. Carmon KS, Loose DS. Secreted frizzled-related protein 4 regulates two Wnt7a signaling pathways and inhibits proliferation in endometrial cancer cells. $\mathrm{Mol}$ Cancer Res (2008) 6(6):1017-28. doi: 10.1158/1541-7786.MCR-08-0039

14. Wang A, Jiao H, Wu J, Wang X, Li J, et al. Expression changes of EGFR, c-Met and Ki67 in gastric cancer and their clinical significance. J Shandong Med (2017) 57 (8):75-6. doi: 10.3969/j.issn.1002266X.2017.08.024

15. Siegel R, Desantis C, Jemal A. Colorectal cancer statistics, 2014. Ca-a Cancer J Clinicians (2014) 64(2):104-17. doi: 10.3322/caac.21220

Conflict of Interest: The authors declare that the research was conducted in the absence of any commercial or financial relationships that could be construed as a potential conflict of interest.

Copyright (c) $2021 \mathrm{Li}$, Dou, Sun, Xie, Li and Cui. This is an open-access article distributed under the terms of the Creative Commons Attribution License (CC BY). The use, distribution or reproduction in other forums is permitted, provided the original author(s) and the copyright owner(s) are credited and that the original publication in this journal is cited, in accordance with accepted academic practice. No use, distribution or reproduction is permitted which does not comply with these terms. 